\title{
Accelerated aging study of ultra high molecular weight polyethylene yarn and unidirectional composites for ballistic applications
}

\author{
S. Chabba · M. van Es · E. J. van Klinken • \\ M. J. Jongedijk · D. Vanek · P. Gijsman • \\ A. C. L. M. van der Waals
}

Received: 12 February 2007 / Accepted: 15 February 2007/Published online: 20 March 2007

(C) Springer Science+Business Media, LLC 2007

Today's armor systems use a variety of polymeric materials to provide excellent ballistic protection combined with low weight and enhanced mobility both for people and vehicles. Typical polymeric materials used in ballistic applications are ultra high molecular weight polyethylene such as Dyneema ${ }^{\circledR}$ and para-aramid fibers such as Kev$\operatorname{lar}^{\circledR}$ and Twaron ${ }^{\circledR}$. Law enforcement professionals and soldiers use protective vests while performing their duty over a wide variety of environmental conditions. These conditions demand the armor systems to withstand and perform well under different environmental conditions. Recent past incidents have highlighted failures associated with Polybenzobisoxazole (PBO) based fibers, highlighting the importance of robustness of the body armor. In a subsequent investigation conducted by National Institute of Justice (NIJ), USA, it has been shown that PBO fibers suffer severe tensile loss when exposed to light and moisture [1]. This loss in tensile properties may result in reduced ballistic protection of PBO based armor solutions during usage. Synthetic fiber properties, performance and stability are critically related to their polymer chemistry. Dyneema ${ }^{\circledR}$ is a high performance polyethylene based fiber produced using a proprietary gel spinning process by DSM Dyneema in The Netherlands and USA. The fiber has extremely high crystallinity and orientation and very

Dyneema ${ }^{\circledR}$ is a trademark owned by Royal DSM N.V. All other trademarks are the property of their respective owners.

S. Chabba $(\varangle) \cdot$ M. van Es · E. J. van Klinken ·

M. J. Jongedijk - D. Vanek - A. C. L. M. van der Waals

DSM Dyneema BV, Urmond, The Netherlands

e-mail:shitij.chabba@dsm.com

P. Gijsman

DSM Research, Geleen, The Netherlands low density making it an attractive solution for lightweight ballistic composite applications. Chemically, Dyneema ${ }^{\circledR}$ fibers do not contain any aromatic, amide or other chemical groups that can react with common chemicals. Hence the fiber's inertness and stability [2]. This study evaluates the performance retention of ultra high molecular weight polyethylene yarns and composites using accelerated aging technique at elevated temperature and humidity conditions.

Ultra high molecular weight polyethylene yarn and unidirectional (UD) composites used in this study were manufactured by DSM Dyneema. Dyneema ${ }^{\circledR}$ SK76 yarn, 1760dtex and Dyneema ${ }^{\circledR}$ UD grades, SB21, SB31 and SB61 were used in the study. Dtex is a standard textile measurement used to express the linear density of the yarn as weight in grams per $10,000 \mathrm{~m}$ length. UD materials Dyneema $^{\circledR}$ SB21, SB31 and SB61 are constructed using ultra high molecular weight polyethylene yarn in an elastomer-based thermoplastic matrix system.

In order to determine the time required for accelerated aging, the oxygen uptake of Dyneema ${ }^{\circledR}$ yarn and UD was monitored as a function of time under well controlled temperature conditions. Oxidation is the most important process for polyolefins that contributes towards aging [3]. The temperature dependence for the rate of chemical reactions can be expressed by the Arrhenius equation [4]:

$k=A e^{\frac{-E_{\mathrm{a}}}{R T}}$

where $k=$ reaction rate constant; $E_{\mathrm{a}}=$ activation energy; $A=$ collision frequency factor; $R=$ gas constant; $T=$ absolute temperature.

The shift factor for a reaction indicates how fast a reaction will occur at the desired temperature in compari- 
son to a base reference temperature. The shift factor for the reaction can be derived from Eq. 1 and is shown below in Eq. 2:

$\ln ($ Shift factor $)=\ln \left(k / k_{\text {ref }}\right)=E_{\mathrm{a}} / R\left(1 / T_{\text {ref }}-1 / T\right)$

where $k_{\text {ref }}=$ reaction rate constant at the reference temperature $T_{\text {ref }} ; k=$ reaction rate constant at temperature $T$.

By plotting $\ln$ (Shift factor) as a function of $1 / T$ a straight line is obtained with the slope equal to $-E_{\mathrm{a}} / R$. This plot is commonly known as Arrhenius plot. Arrhenius plots for Dyneema ${ }^{\circledR}$ SK76 and Dyneema ${ }^{\circledR}$ SB21 are shown in Figs. 1 and 2.

In this study, $100 \mathrm{~m}$ of yarn was wound on a perforated bobbin. Ballistic packs measuring $40 \times 40 \mathrm{~cm}$ with an areal density of $3.66 \mathrm{~kg} / \mathrm{m}^{2}$ were prepared for each UD material. Five years at $35^{\circ} \mathrm{C}$ temperature could be considered a typical baseline requirement for ballistic vests. During regular wear a vest is likely to be exposed to high relative humidity levels. Hence to maintain a high relative humidity as experienced in a vest, it was decided to use $80 \%$ relative humidity for aging study. Using Eq. 2 and Figs. 1 and 2, it can be calculated that 8 weeks at $65^{\circ} \mathrm{C}$ will accelerate the aging to create the same effect as 5 years at $35{ }^{\circ} \mathrm{C}$ base temperature. Control and aged yarn samples were characterized for their tensile properties in accordance with modified ISO 2062 standard. Samples were conditioned at $23{ }^{\circ} \mathrm{C}$ and $55 \%$ relative humidity for $72 \mathrm{~h}$ before testing. Tensile test specimens were tested at a gauge length of $500 \mathrm{~mm}$ and at a crosshead speed of $250 \mathrm{~mm} / \mathrm{min}$ on Zwick1120 tensile testing equipment. Twenty specimens were tested for each yarn type to measure the tenacity, fracture strain and Young's modulus. Six ballistic packages of Dyneema ${ }^{\circledR}$ UD grades SB21, SB31 and SB61 were tested to measure the $V_{50}$ (velocity at which there is a $50 \%$ probability that the bullet will penetrate the ballistic package) as per STANAG 2920 method. A $9 \mathrm{~mm}$ steel jacketed bullet was used for ballistic testing and the

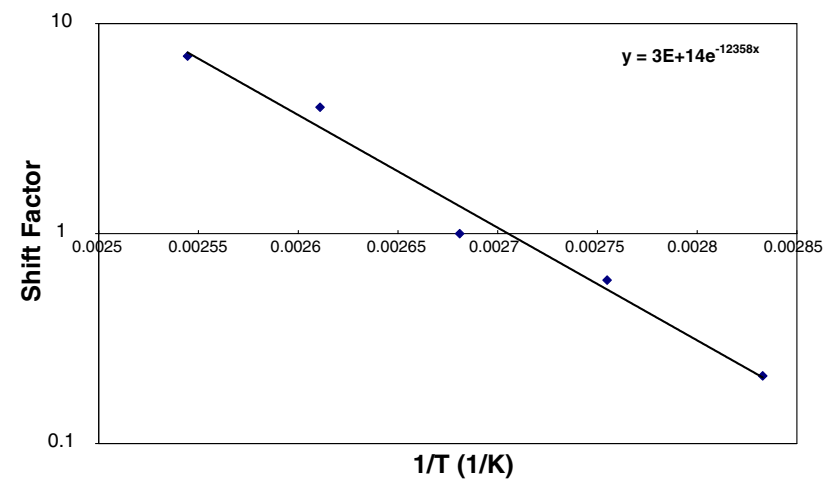

Fig. 1 Arrhenius Plot for Dyneema ${ }^{\circledR}$ SK76 yarn

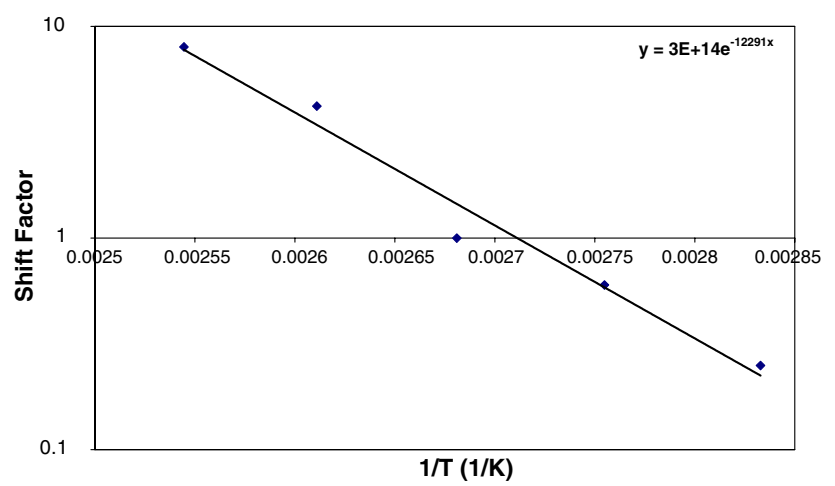

Fig. 2 Arrhenius Plot for Dyneema ${ }^{\circledR}$ SB21

test set up followed the standard STANAG 2920 recommendations. Tensile and ballistic tests were conducted after $0,1,2,4$ and 8 weeks of accelerated aging at $65^{\circ} \mathrm{C}$ and $80 \%$ relative humidity.

Figure 3 shows the effect of aging time on tenacity, strain to break and Young's modulus for Dyneema ${ }^{\circledR}$ SK76 yarn. As can be seen from Fig. 3, the strain to break increases from 0 to 8 weeks. This increase can be attributed to the relaxation of highly oriented molecular chains of ultra high molecular weight polyethylene on constant exposure at $65{ }^{\circ} \mathrm{C}$ and $80 \%$ R.H. for 8 weeks. The yarn tenacity shows little variation over the 8 weeks of accelerated aging. Young's modulus for the yarn changes from 100 to $92.4 \%$ after 8 weeks of accelerated aging. The combined results indicate that Dyneema ${ }^{\circledR}$ SK76 exhibits good stability and property retention after 8 weeks of accelerated aging at an elevated temperature and humidity.

The National Institute of Justice (NIJ), USA, recently published tensile strength retention results for PBO yarn upon exposure to high temperature and humidity [1]. PBO yarn showed almost 20\% drop in tensile strength after 50 days of exposure at $50{ }^{\circ} \mathrm{C}$ and $60 \%$ relative humidity.

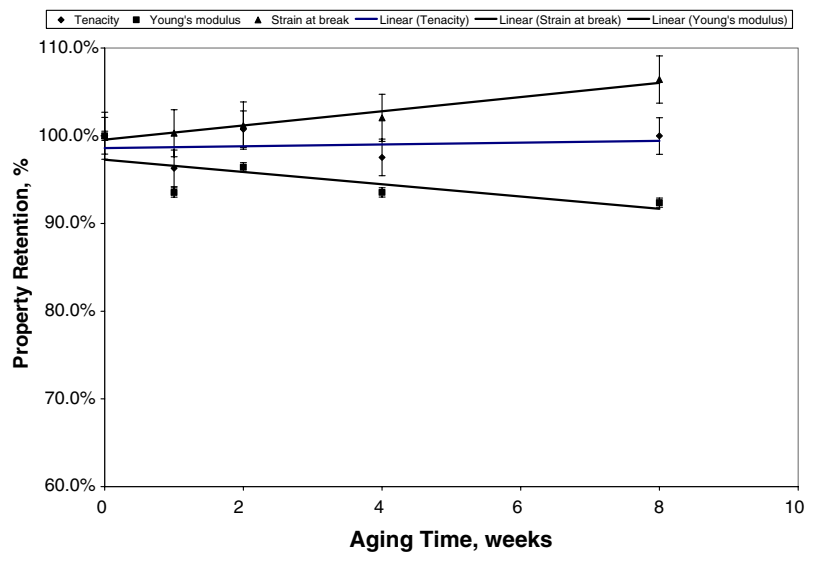

Fig. 3 Effect of accelerated aging at $65{ }^{\circ} \mathrm{C}$ and $80 \%$ R.H. on Dyneema ${ }^{\circledR}$ SK76 yarn 
As can be seen clearly from Fig. 3, Dyneema ${ }^{\circledR}$ SK76 yarn shows more than $97 \%$ tensile strength retention after 8 weeks of accelerated aging at higher temperature and relative humidity.

A composite armor system is more efficient if it can absorb the projectile impact energy faster and spread it over a larger surface area quickly. Cunniff developed an empirical relationship that related the ballistic performance parameter $U^{*}$ with fiber tensile properties [5]:

$$
U^{*}=\frac{\sigma_{\mathrm{f}} \varepsilon_{\mathrm{f}}}{2 \rho} \sqrt{\frac{E}{\rho}}
$$

where $\sigma_{\mathrm{f}}=$ fiber tensile strength at break; $\varepsilon_{\mathrm{f}}=$ fiber strain at break; $\rho=$ fiber density.

As can be seen from Fig. 3, the yarn tenacity and strain to failure show little change over the 8 weeks of accelerated aging. This further confirms that Dyneema ${ }^{\circledR}$ yarns do not lose their specific energy absorption capabilities after 8 weeks of accelerated aging and offer a good solution for ballistic applications.

Figure 4 shows the relative change in $V_{50}$ for Dyneema ${ }^{\circledR}$ SB21, SB31 and SB61 composites after accelerated aging at $65{ }^{\circ} \mathrm{C}$ and $80 \%$ R.H. for 8 weeks. As can be seen from Fig. 4 , all UD materials retain their $V_{50}$ performance after 8 weeks of accelerated aging. One way ANOVA analysis showed no significant change in $V_{50}$ value from 0 to 8 weeks for Dyneema ${ }^{\circledR}$ SB21, SB31 and SB61 at 95\% confidence interval. These results indicate the excellent retention of ballistic properties for Dyneema ${ }^{\circledR} \mathrm{UD}$.

The results indicate that both ultra high molecular weight polyethylene based Dyneema ${ }^{\circledR}$ yarn and UD materials retain their tensile properties and ballistic $\left(V_{50}\right)$ performance for 5 years at $35^{\circ} \mathrm{C}$. This indicates good life time expectancy for both Dyneema ${ }^{\circledR}$ yarn and UD materials. However, the life time expectancy for a composite armor system is a complex evaluation. The actual long term performance of composite body armor will depend on factors which cannot be easily evaluated in a laboratory

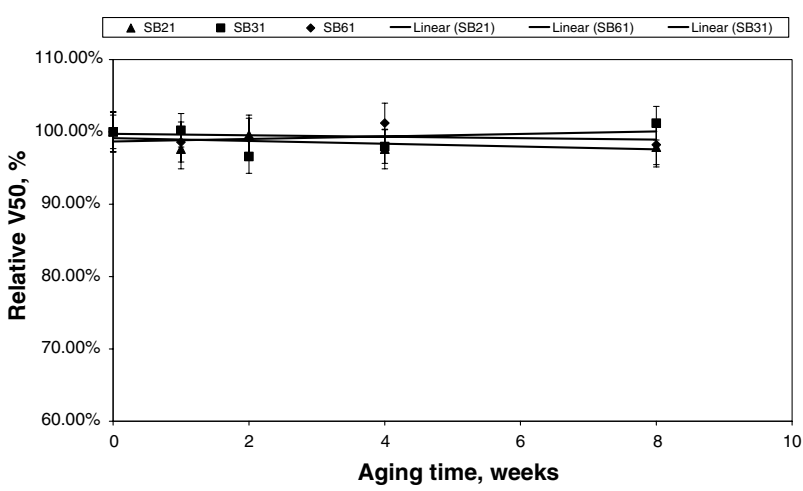

Fig. 4 Effect of accelerated aging at $65{ }^{\circ} \mathrm{C}$ and $80 \%$ R.H. on $V_{50}$ of Dyneema ${ }^{\circledR}$ SB21, SB31 and SB61

setting such as vest design, vest care, etc. It is recommended that for further understanding of life time expectancy of ballistic armor systems, the field used armor is evaluated for its performance retention after regular intervals. The measured performance of the used body armor should be correlated with the results obtained under a laboratory environment. This analysis will help to generate suitable testing methods that may allow to better predict the performance retention of body armor over its lifecycle.

\section{References}

1. "Third status report to the Attorney General on Body Armor Safety Initiative Testing and Activities, August 2005, National Institute of Justice, USA', http://www.ojp.usdoj.gov/bvpbasi/ docs/SupplementII_08_12_05.pdf, as on November 20, 2006

2. Van Dingenen JLJ (2004) In: Hearle JWS (ed) High-performance fibers. Woodhead Publishing Limited, Cambridge, England, p 76

3. Gugumus F (1990) In: Gachter R, Muller H (eds) Plastic additives handbook. Hanser Publisher, New York, p 1

4. Rodriguez F (1996) In: Principles of polymer systems. Taylor \& Francis, Philadelphia, PA, p 104

5. Cunniff PM, Auerbach MA (2002) 23rd Army science conference, Orlando, FL, December 2002 